\title{
Education for future biobankers - The state-of-the-art and outlook
}

\author{
Judita Kinkorová ${ }^{1,2}$
}

Received: 18 December 2020 / Accepted: 27 January 2021 / Published online: 10 March 2021

(c) European Association for Predictive, Preventive and Personalised Medicine (EPMA) 2021

\begin{abstract}
Biobanking as a quickly growing branch of personalised medicine has undergone enormous progress during last two decades. Nowadays it is a well developed and structured multidisciplinary field that reflects developments and advances of biomedical research based on principles of predictive, preventive and personalised medicine (PPPM/3PM). All these trends in PPPM progress have to be translated into practice and education of new generation of scientists and healthcare givers. The importance of biobanks for multitasking research, personalised treatment, and health care systems was emphasised by many scientists and health care experts. As biobanking carries multidisciplinary character currently including more professionals than ten-twenty years ago, new generation of professional biobankers is urgently needed. To create new generation of biobankers who are fully competent to answer more and more scientific and practical questions, new study programmes, novel university curricula, and topic-dedicated courses are essential. The aim of the review is to present basic forms, trends of biobanking education offered by various biobanking related bodies and to highlight future needs. The first step is to cover all activities and duties of biobanks: acquiring, collecting, storageing and sharing biological samples and associated data, using adequate assessment for both - materials and data, taking into consideration ethical, legal, and societal issues (ELSI), responding to all stakeholder needs including pharmaceutical and other related industries, patient organisations and many other interested groups, emerging technologies and innovations as well as current and future requirements of health care systems. To compile educational programmes is a comprehensive task for all actors involved in the field of biobanking who contribute to the harmonised process of creating high educational level for future generation of biobankers. The exchange of experience involving extensive international collaboration is the way how to facilitate the process of creating optimal biobanking education.
\end{abstract}

Keywords Biobank · Education · Training · Predictive preventive personalised medicine (PPPM/3PM) - Ethical legal and societal issues (ELSI) $\cdot$ Future health care $\cdot$ Artificial intelligence $\cdot$ Machine learning $\cdot$ Innovation $\cdot$ Big data $\cdot$ Biomedical research $\cdot$ Multidisciplinary $\cdot$ Health policy $\cdot$ International collaboration $\cdot$ Healthcare industry $\cdot$ COVID- 19

Abbreviations
ELSI
AI
ML
IT

ISBER
Ethical, legal, and societal issues

Artificial intelligence

Machine learning

Information technology/ies

International Society for Biological and

Environmental Repositories kinkorovaj@fnplzen.cz

1 Laboratory of Immunochemistry, University Hospital in Pilsen, Edvarda Beneše 1128/13, 30599 Pilsen, Czech Republic

2 Faculty of Medicine in Pilsen, Charles University, Husova 3, Pilsen 301 00, Czech Republic
OECD

NCI

CAP

EC

QBRS

ASCP BOC

ESBB

BBMRI-ERIC

Organisation for Economic Co-operation and Development

National Cancer Institute

College of American Pathologists

European Commission

Qualification in Repository Science

American Society for Clinical Pathology

Board of Certification

European, Middle Eastern \& Afri-

can Society for Biopreservation and

Biobanking

Biobanking and Biomolecular Resources

Research Infrastructure- European

Research Infrastructure Consortium

EPMA European Association for Predictive,

Preventive and Personalised Medicine 


$\begin{array}{ll}\text { PPPM } & \begin{array}{l}\text { Predictive, Preventive and Personalised } \\ \text { Medicine }\end{array} \\ \text { QC/QA } & \begin{array}{l}\text { Quality control, quality assessment } \\ \text { European Virus Archive - Global }\end{array} \\ \text { EVAg } & \begin{array}{l}\text { International Agency for Research on } \\ \text { IARC }\end{array} \\ & \text { Cancer } \\ \text { WHO } & \text { World Health Organization } \\ \text { EMEA } & \text { Europe, Middle East, and Africa } \\ \text { LMIC } & \text { Low- and middle-income countries } \\ \text { LIMS } & \text { Laboratory information management } \\ & \text { system } \\ \text { GDPR } & \text { General Data Protection Regulation }\end{array}$

\section{Introduction}

Biobanking for the last more than 20 years represents a significant pillar of personalised medicine approach to the patient health care with high innovative potential. Basic attributes of predictive, preventive and personalised medicine (PPPM) meet the requirements of modern biobanking to better prevent, to contribute to the early diagnosis, to find the best possible treatment for every patient, to predict the patient response.

Currently hundreds of well-established biobanks operate worldwide, and new biobanks are being established. Biobanks are generally based on biological samples and associated data, and biobanking as rapidly developing science is multidisciplinary, requiring clinicians, surgery doctors, laboratory staff, pathologists, imaging specialists as well as information technologies (IT) specialists, statisticians, data and „big data” specialists, artificial intelligence (AI), and machine learning (ML) specialists. Biobanking also includes other specializations such as engineering, ethics, laws, logistics, and business management [1]. Every process in biobank during the whole life cycle of a sample, from collecting biological material, transfer, storage, sharing, requires highly specialised and qualified personnel. As regards associated data and information, accurate, reliable, and standardised clinical and laboratory data are required [2].

To operate a biobank fully and reliably, new generation of biobankers is needed.

Together with biobanking and a science of biobanking development the requirements on the biobanking staff are bigger and bigger and more diverse. During last two decades many more-or-less successful educational attempts were developed. From relatively small simple courses for specific staff specializations like technicians, clinicians, IT specialists, to bigger and more comprehensive ones. The type and extent were dependent on the type of biobank, from population, or disease specific and other human biobank, to animal repositories, seed biobanks and fungi and other microorganisms' biorepositories, museums, and environmental repositories. Courses or education classes, workshops and other events also depend on the provider of the course, it means university, hospital, society, or association, and others. Some courses are free, but many are paid. Some courses are only theoretical, some with deep laboratory exercise and trainings. The challenge is how to develop an appropriate range of education and training opportunities for the diverse needs of biobank employee [3].

\section{History of biobanking education}

Just over a decade ago, no formal biobank education programs for biobanking existed [3], but the need of education was expressed by pathologists, researchers, and scientists. The first actors in the field of formulating biobanking educational programs were International Society for Biological and Environmental Repositories (ISBER), National Cancer Institute (NCI), Organisation for Economic Co-operation and Development (OECD), and European Commission (EC). OECD published in 2007 OECD Principles and Guidelines for Access to Research Data from Public Funding [4], and in 2009 OECD Guidelines for Human Biobanks and Genetic Research [5]. NCI published in 2016 NCI Best Practices for Biospecimen Resources [6] with the Appendix 6: CAP Biorepository Accreditation Program Checklist (CAP- College of American Pathologists) that can be considered as the cornerstone of biobanking with comments on education and training.

The form of education can be diverse; from lectures, lessons, seminars, workshops with a special narrow ranged topic, to one or more weeks, months, years courses are being currently available. Well known and established world - famous biobanks offer their own specialised courses, university degree studies, $\mathrm{PhD}$ courses, and other types of education and training [3, 7-11].

Biobanking is a good example of implementation so called "mobile learning", "e-learning", "distance learning" $[12,13]$, as a type that could be realised by the use of mobile technologies. Very popular are various electronic, so called e-learning courses, allowing communication in real time, or in non-real time- offline to share with students study materials, presentations, tests, references, annotations, links, videos, sharing screens, consultations, and so on, via electronic media, such as the internet, intranets, extranets, satellite broadcast, audio/video tape, interactive TV and CDROM. E-learning is commonly defined as using technological devices and the internet for teaching and learning [12]. The need for a wide use of IT and IA technologies refers to the growing amount of data in biobanks, that are of big value, variety, and velocity [14], and generated by various sources [15]. International dimension of biobanking as a 
science, requires broad international collaboration, and the number of professional specializations involved in biobanking (Fig. 1). Biobanking education is personalised education to fit the specialization and the purpose $[16,17]$.

\section{Three biggest biobanking societies and infrastructure international educational courses}

- ISBER education (International Society for Biological and Environmental Repositories)

ISBER is a global biobanking organization which creates opportunities for networking, education, and innovations and harmonises approaches to evolving challenges in biological and environmental repositories. ISBER fosters collaboration, creates education and training opportunities [18], provides an international showcase for state-of-the-art policies, processes, and research findings, and innovative technologies, products, and services. Together, these activities promote best practices that cut across the broad range of repositories that ISBER serves [19]. For ISBER as it has declared on its home web pages education activities are of great importance. The second out of six society goals are: Educate and share information and tools within the society and with stakeholders. Learning in ISBER is divided into several types of activities: educational videos presented by ISBER expert members specialised e.g., on data management, ethical, legal, and societal issues (ELSI), quality management, packing and shipping, educational webinars, also specialised on ISBER best practices, SPREC (Standard PREanalytical Coding for Biospecimens), biobanking software, veterinary biobank, and educational courses. The most important are following three courses:

Essentials of Biobanking Course - ISBER with Canadian Tissue Repository Network (CTRNet) offer online flexible format course with 9 modules, $7-11 \mathrm{~h}$ to review all material and complete, international, applicable for all biobankers, human biobanks focused (paid) (Annual Report 2019) [8].

Educational Opportunities/Certificates and Degrees for Repositories offer a list of available courses in USA (7 courses), Europe (10 courses), Canada (2 courses), and 2 international, lasting from days to two years or varies [20].

The most recent course is Qualification in Repository Science (QBRS). ISBER and American Society for Clinical

Fig. 1 Complex approach to biobanking education

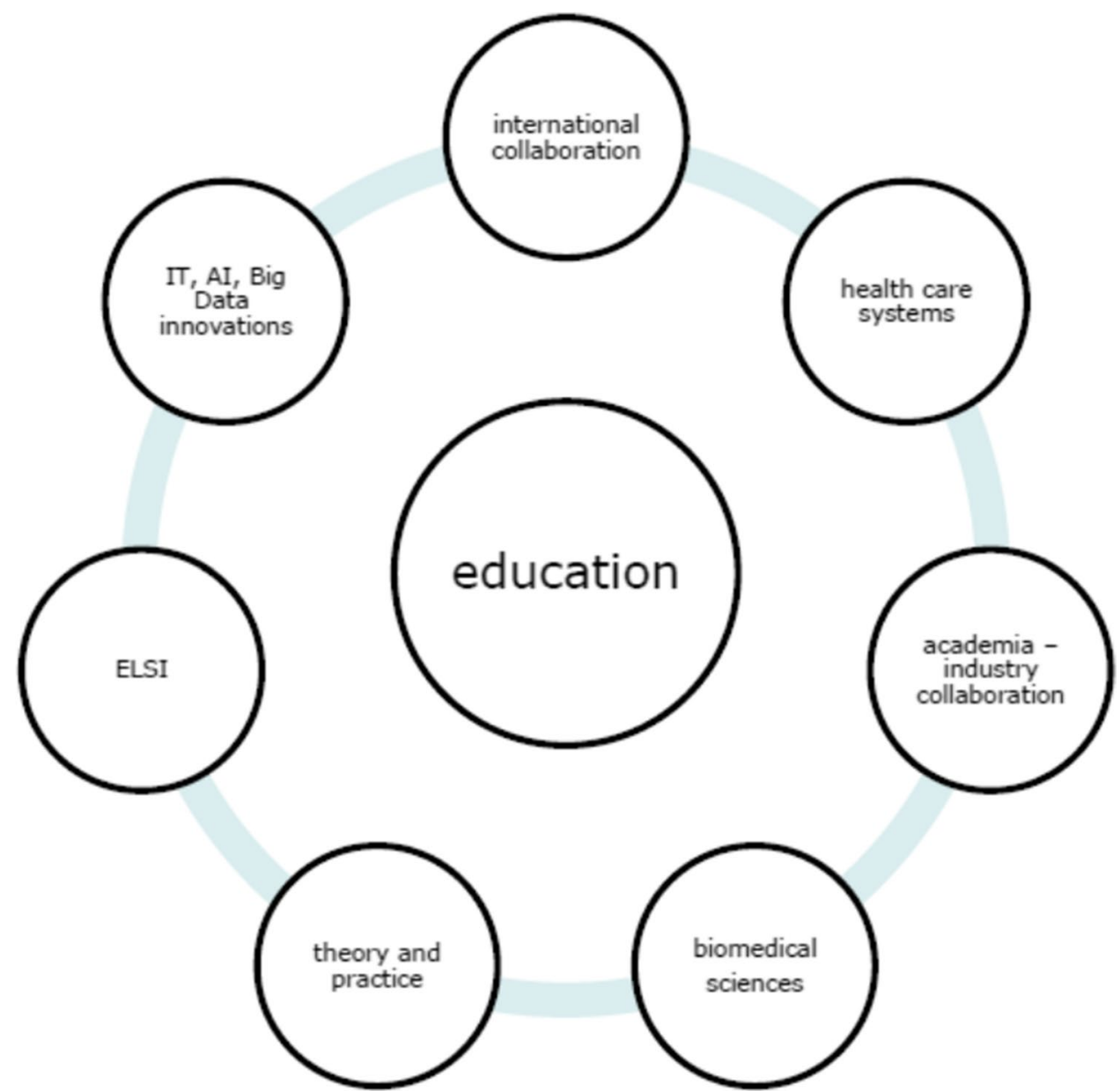


Pathology Board of Certification (ASCP BOC) prepared a new Qualification in Repository Science (QBRS) for biobankers. QBRS is a special professional course for advanced biobankers including all the qualifications, knowledge, and skills to become a competent biorepository scientist. The course consists of activities such as specimen handling (collection, processing, and storage), sample/data inventory and safety management and quality control, infection control, and biorepository operations. QBRS started in April 2020 [21]. QBRS was designed upon meeting specific educational and experience requirements for the qualification, candidates. This new qualification will further advance the field of biorepository science. Biobanks are vital to medical research and precision medicine and require qualified professionals to obtain high quality results that will be useful in advancing biomedicine [21].

Summary of ISBER educational activities was recently published in the Journal of Society: Biopreservation and Biobanking, 2020 [3].

- ESBB education (European, Middle Eastern \& African Society for Biopreservation and Biobanking)

ESBB is focused on the three regions Europe, Middle East, and Africa (EMEA) and the mission emphasises advance biosharing for a better world through mobilising, inspiring, and educating the biobank community across EMEA [22]. ESBB offers several options to educate like webinars, courses, and mentoring and exchange programs [23].

ESBB student webinar focuses on Biobank Master Students but is open for all students, young biobankers and/or advanced biobankers, independent of their career level. The aim is that Master Students in their final year take different roles in this webinar series in order to gain experiences while presenting a talk, or chairing a session, while being supervised by senior biobank professionals [23].

ESBB education webinars on various topics for the year 2020 were as follows: project management I, II, ELSI, requirement management for IT solutions, automation in biobanking, quality management \& pre-analytics, change management I, II, clinical trials, translational research and biobanking.

- BBMRI-ERIC education (Biobanking and Biomolecular Resources Research Infrastructure- European Research Infrastructure Consortium)

BBMRI-ERIC is the biggest biobanking infrastructure in Europe (with 16 members mainly EU states and 4 observers) [24].

BBMRI as the entire infrastructure of research centres, universities, biobanks, industry does not organise its own education courses, but organises thematically focused webinars, usually on hot topics like ethical, legal, and societal issues (ELSI), quality management issues, and training courses. For external researchers, medical professionals, biobank managers who want to participate in research projects on human biological samples offers external ELSI training courses. Five days and consists of two modules: the first module is focused on ethical, legal, and regulatory questions and the process how to gain a counsel for research projects since regulations vary widely between European countries. In addition, for genetic data from human samples it provides practical guidelines on how to manage them. The second module deals with procurement of samples and data in a lifecycle of the sample in a clinical context aligned with latest CEN/ISO standards for preanalytical procedures [25]. BBMRI also offers series of videos from various thematically focused events to address the key issues in biomedical research involving human subjects, human biological samples and associated medical data: ethics, legal issues, privacy and data protection, data standardisation.

\section{Bilateral educational programs}

BRoTHER Education "bottom up" (Biobank Research on Telemedical Approaches for Human Biobanks in a European Region).

Project of cross border collaboration BRoTHER (between Bavaria, Germany, and the Czech Republic) is an example of other "bottom up" activities in the field of biobank education. Education of medical student in the frame of active student exchange program was a part of collaborative activities between the two regions, health care systems, medical institutions, and biobanks. The BRoTHER project (2017-2019) was designed to analyse [26] the obstacles which have to be overcome if clinical related biobanks from different national systems wish to collaborate and set up common biobank projects. Successful collaboration can unable forming an innovative nucleus in the Centre of Europe for future interconnected biobanks, as was published in Pan European Networks in 2017 [26]. The evaluation of the project resulted to the development of a subsequent project with a special attention to the education in biobanking - edu-BRoTHER supported by a European Union grant within the INTERREG programme (ETZ 2014-2020/289) [27].

\section{Other national educational and training courses}

In addition to that educational activities of societies, universities, biobanks, research centres, also national and regional educational programs are being developed based on national and regional requirements and needs. 
In Poland, the first training course was organised in 2004 in collaboration with the University of Barcelona [10].

Integrated BioBank of Luxemboug (IBBL) developed in collaboration with the University of Luxembourg a long-life learning course that includes theoretical, operational, and practical knowledge and skills necessary for biobanks functioning. The certificate program lasts 3 weeks and besides the basic biobanking skills encourages the information for international material and data exchange across different thematic biobanking groups involved in biospecimen conservation, storage, science, and research.

The first course took place in 2011 and since has been offered every two years [7].

Medical University in Graz and BioBank Graz (Austria) prepared and offer first distance learning postgraduate Master course "MSc in Biobanking", that started in 2016. The course is organised as four semesters course and the curriculum is comprised of 12 modules. The first two years the course is realised as a distance-learning, and the students can do their training alongside full-time work anywhere in the world. One-week face-to face course takes place in Graz each semester [28].

Two-year systematic training program at the Master level was developed in 2010, as a joint initiative of the Catholic University in Lyon and the University of Nice Sophia Antipolis (France). [29], The course "Biobank Manager" focuses on practical skills such as quality control and quality assessment (QC/QA), the management of bioresources, how to get funding for a biobank, how to get material transfer agreement (MTA), how to conduct a translational or clinical research program.

European Virus Archive - Global (EVAg is a non-profit organization a unique biological resource in the field of virology, offers Biobanking E-learning Training for students mainly from Africa [30].

International Agency for Research on Cancer (IARC) World Health Organization (WHO) Also offers "Learning platform Biobanking" that consists of IT infrastructures for biobanks, sample and data collection, sample and data management, bioinformatics, ELSI, quality and sustainability [31].

China has entered to the biobanking world during last decade vigorously and in a short time has become an important biobanking partner. The expansion of biobanks in China as well as in other countries requires educated staff. Leading professors from China, the USA, UK, and Canada were invited to teach the latest version of biobanking knowledge and skills around the globe [9]. One example is a comprehensive course, consisting of 6 modules: basic medical sciences, clinical medicine, life sciences, mechanical engineering, and biomedical engineering and was inspired by French well established 2-year training program at the Master level with a professional qualification as a "Biobank Manager" [32].

In Arab region, where biobanking is a relatively new concept [11] newly established biobanking courses cover quality, ethics, information technology, translational research. Other countries in EMEA region with fast growing biobanks are Egypt [33], Jordan [34], Qatar [35, 36], and Saudi Arabia [37].

\section{Non biobanking societies, associations, and other educational bodies}

EPMA Education (European Association for Predictive, Preventive and Personalised Medicine).

The EPMA is a world-famous institution that promotes predictive, preventive, and personalised approaches and principles in health care, health care systems, biomedical research, and education of future generations of professionals in Europe and worldwide. EPMA is based on active integrative, and multidisciplinary approach in its activities [38]. An important portion of EPMA activities is devoted to young professionals. For them wide range of topics is offered with the aim to introduce young researchers to the field of Predictive and Personalised Medicine and main principals of PPPM (in order to help medical schools), support students to be involved and actively participate in national and international research projects and collaborations between young scientists and between Universities, research laboratories and Pharma and Technological companies to build multifunctioning international network.

Since 2009 EPMA has been publishing EPMA Journal with specialised professional sections, among them "Biobanking and biopreservation" [39].

\section{European Commission and education in the field of biobanking}

Basic requirements on biobank and their basic functions were published in Directive 2004/23/EC [40] and Directive 2006/86/EC that implements the Directive 2004/23/EC. The article 27 of Directive 2004/23/EC describes the basic requirements on personnel involved in donation, procurement, testing, processing, preservation, storage and distribution of human tissues and cells.

Based on the above Directives some member states developed their own national education courses answering their own national as well as requirements.

European Commission generally supports all kinds of knowledge and experience sharing and dissemination, but 
there is no special tool or program. Every pillar of Horizon 2020 - the biggest EU research and innovation program ever [41] (excellent science, industrial leadership, societal challenges) has its own approach and the instruments for international education and experience sharing are spreading excellence and widening participation e.g. Teaming, Twinning, and ERA-Chairs.

\section{Horizon 2020 projects with education in biobanking}

- B3Africa. Bridging Biobanking and Biomedical Research across Europe and Africa aims to support, develop, and establish predictive, preventive, and personalised healthcare worldwide. Newly established 30 African biobanks, are an invaluable resource of human samples and data. The African population represents the greatest genomic diversity on the planet and offers an enormous resource of information to enhance biomedical research. Implementation of an education and training programs for information and capacity building is therefore of great importance [42].

- DRYNET. The project supports the development of international/inter-sectorial network, with the aim of sharing knowhow \& expertise for the dry storage of cells/ germplasm. A part of the project is also meeting/workshop/summer school to implement the project strategy for biobanking. DRYNET aim to generate young scientists with transferable skills, ensuring career prospect in academia/industry [43].

- DRYSTORE. The proposal is perfectly fitted for the "Researcher" to become an independent scientist and an expert in the field of biobanking supporting researchers' creative potential and further development of interdisciplinary and communication skills by learning Somatic Cell Nuclear Transfer (SCNT). The project includes whole genome analysis, mentoring students, participating in conferences, and communicating research results to targeted audiences, and due to enhancing scientific profile of the researcher [44].

- SPIDIA4P. The aim of the project is to enable better diagnosis and medical research for personalised medicine and a part of the project is the organisation of training, education, and counselling [45].

- SIMICA. In the frame of twinning project, it will offer training and mentoring opportunities for young researchers from partnering institutions [46].

- WIDENLIFE. University of Tartu aims to become the leading research and teaching centre for reproductive and foetal medicine in Eastern and Nordic European countries. It will also offer training and mentoring opportunities for young researchers [47].

- LIFECYCLE. The aim of the project is to regularly organise international meetings focused on pregnancy and child cohort researchers, and to introduce a Fellowship Training Program for exchange of junior researchers between European pregnancy or child cohorts. Finally to develop e-learning modules for researchers performing life-course health studies [48].

- BonePain. BonePain is the first European platform to promote research, innovation and education focused on bone pain. It consists of creating a wide-ranging integrated training program for young researchers. The main topics are to elucidate the mechanisms of bone pain and develop new medicines with the use of in vivo models, cancer-induced bone pain and fracture pain to investigate the pathophysiology and modern treatment strategies. Extensive trainings will cover both specific research skills and transferable skills, and the students will obtain an interdisciplinary, state-of-the-art, and innovative training from the experts, with international experience [49].

- Biotem. Project that is historically focused on educational and research purposes has evolved in terms of complexity and demand due to the most recent developments in biomedical research and therapy and follows a trend towards an era of personalised medicine [50].

- TrainCKDis. TrainCKDis is a European Training Network supporting 15 young researchers working on research projects targeting key areas required to fill the gaps in chronic kidney disease CKD characterization. Enhanced understanding will support the identification of biomarkers for early diagnosis of patients most at risk, for monitoring progression, as well as aid in development of treatments [51].

\section{Companies operating in biobanking and specialised biobanking education}

Big companies connected and supporting biobanking processes offer educational and study programmes in great variety: Thermo Fisher [52] is a good example offering their "Biobanking Learning Center". Agilent [53] offers wide range of educational activities at Agilent University including classroom training, virtual instructor-led training, and self-paced e-learning courses. Autoscribe [54] propose a range of laboratory information management system (LIMS) training courses and workshops, Bruker's education and training programs [55] get access to knowledge about the very latest achievements in modern analytics. Farrarscientific [56] also offers hand on training and teaching on all their products. Fluidigm [57] offers several training programmes such as basic training for beginners, one-day training, and consulting all about Fluidigm instrument's processes and applications. LabVantage [58] offers variety of training courses from in-person or live online training to virtual about laboratory informatics and technology. Swift 
Biosciences [59] offers summer webinar series with attractive topics as next generation sequencing of DNA and RNA samples.

\section{Role of biobanking in the future healthcare}

Future healthcare will be more personalised, precision and more based on personal data and information. Future health care will be more targeting the optimalization and prolongation of wellness [60]. This era high-throughput technologies, allows collection and analysis of huge, disparate datasets on individual health [61], and aiming the prediction, prevention, early diagnosis, and treatment precisely personalised. Biobanks currently and in the future will collect and store millions of samples associated with data and information that will contribute to more precise patients' stratification and defining vulnerable groups of patients. Knowledge stored in biobanks will enhance preventive approaches, early and precise diagnosis, focused treatment and follow up. It will also serve as a supportive base for development of new drugs. Of exceptional importance are samples from rare diseases patients in biobanks, where wide international collaboration and samples exchange is crucial. Biobanks specialised on special diagnoses (cancers, diabetes, neurodegenerative diseases), special patients' groups (children, ethnic races, pregnant women), and recently on human microbiom are ready to contribute to better health care.

Well established and sustainable biobanks allow costeffective, and affordable health care.

Patient involvement and public awareness of the role of biobanks in health care is one of the future missions of future generation of biobankers.

\section{Current and future challenges of biobanking}

Modern biobanks function as complex infrastructures where clinicians, biologists, nurses, technicians, and bioethicists work together [62], but the spectrum of specializations is much wider.

It is evident, that education in biobanking is a great challenge worldwide. The number and variety of educational activities presents the urgent demand of it. Almost every entity operating in biomedical research and especially in the field of biobanking run and/or develop education that reflects the need of it and its variability and specificity. As biobanking is extremely multidisciplinary, the only way is to educate not only individuals, but biobanking teams consisting of a variety of specialists. Generally accepting idea is the need of gradual education from basic to advanced biobanking education, but the whole research, scientific and practical branch of biobanking requires different employees such as doctors, technical staff, IT specialists, pathologists, biologists, statisticians, and many other.
General data protection regulation (GDPR), a novel EU wide legal framework for the protection of personal data, which entered in force on May 25, 2018 emphasised the legal basis of biobanking and enhanced data sharing for the purpose of stimulating progress in Research. Incorporation these new principles in data management are also challenge for biobanking education.

\section{Machine learning and AI as essential tools in biobanking}

As regards the forms of education there are two main trends, the first one is theoretical that can be realised both personally or in class, but wide using a variety of mobile technologies, artificial intelligence and machine learning tools has been a growing trend for higher education and personalised learning [63]. Practical education can be realised personally at specialised facilities.

Data in biobanks are true "big data", as regards their velocity, variety, and volume. To handle with them efficiently new innovative IT tools and innovative technologies should be involved and used. Biobanking data enable diseases development modelling, management of disease evolution, and dynamics. Data stored in biobanking datasets contribute to compile supportive programs and algorithmsartificial intelligence-for specialist's decision processes. Datasets in biobanks enable data mining according to the special requirements.

\section{Role of biobanking in dealing with pandemic situations}

Corona pandemic in the beginning of 2020 has changed not only normal life but also scientific life of researchers in the manner nobody could imagine before. Scientists have learned a lot, but one of the consequences was that much biobanking work could be done electronically, meeting calls, webinars, video records, without person-to-person meetings. Existing biobanks worldwide opened new departments dedicated to Covid-19 patients's samples, and new initiatives opened biobanks with Covid-19 samples to scientists all over the world to boost development of new vaccines and treatments.

For education and training it means great support for any type of electronic forms and aspects, that is quicker, cheaper, independent on the classroom, world time zone, personal time schedule, and others, and active - real timeinternational communication. The pandemic beside its devastating consequences, strongly supported electronisation and innovation in science, education, and training. Despite these essential advantages there are still laboratory "manual" skills that cannot be realised electronically. So, we are facing new challenges that the Corona pandemic has brought, and 
in some way, it has moved the problem of biobank education and training to the higher level and opened new ways how to better prepare new generation of biobankers for the future including such uninspected situations like pandemics and other disasters could be.

Pandemics has influenced any aspect of biobanking activities. Covid-19 biobanks are new phenomenon with an unpredictable importance for the future research. Whatever we have learned during the Corona pandemic should be quickly processed, evaluated, and prepared to hand over to the new generation of biobankers.

\section{Benefits of biobanking for healthcare and medical research}

Comparing with classical banks, biobanks are ready to answer questions we do not know now. During the relatively short history of biobanks their importance for healthcare and biomedical research is enormous. Biobanks provide a fundamental scientific infrastructure for personalised medicine [64].

Shortage of qualified biobanking professionals is currently felt as the effect of the lack of comprehensive education of future biobankers [9]. The high demand for educating experts in the field of biobanking creates the need for a well-structured training and educational system [17]. A new generation of researchers will also need to be trained in the language and methodology of future research, because the future research will increasingly rely on access to large international collections of various materials [65]. To create and to promote high level of professionalism by new generations of specialists is a prerequisite of effective and fully actionable biobanking worldwide [16]. As biobanking development is closely connected with personalised medicine approaches, principles of predictive, preventive, and personalised medicine (PPPM) must be incorporated in the future education.

Current activities in the forming biobanking courses collect the experience, offer the tools and instruments for future biobankers involving all aspects of biobanking activities (theoretical and practical), and show the education as lifelong learning process. The term "biobanker" thus means a scientist who works in biobank, not only selected specialists like medical doctor, pathologist, technician, etc. who are necessary for biobank operating. It is also evident that different entities like universities, biobanking associations, societies, and other stakeholders contribute to the whole process of forming the optimal biobanking education, that meet actual requirements. Trainings, workshops, courses, and other forms of education cannot replace a professional biobanking education for biobanking personnel but represent ideal supplemental education for scientists [17].

Samples and associated data in biobanks of high quality ensure the quality and veracity of research results and reproducibility of research results.

Data and information stored in biobanks are invaluable sources for evaluating demography and lifestyle, history of

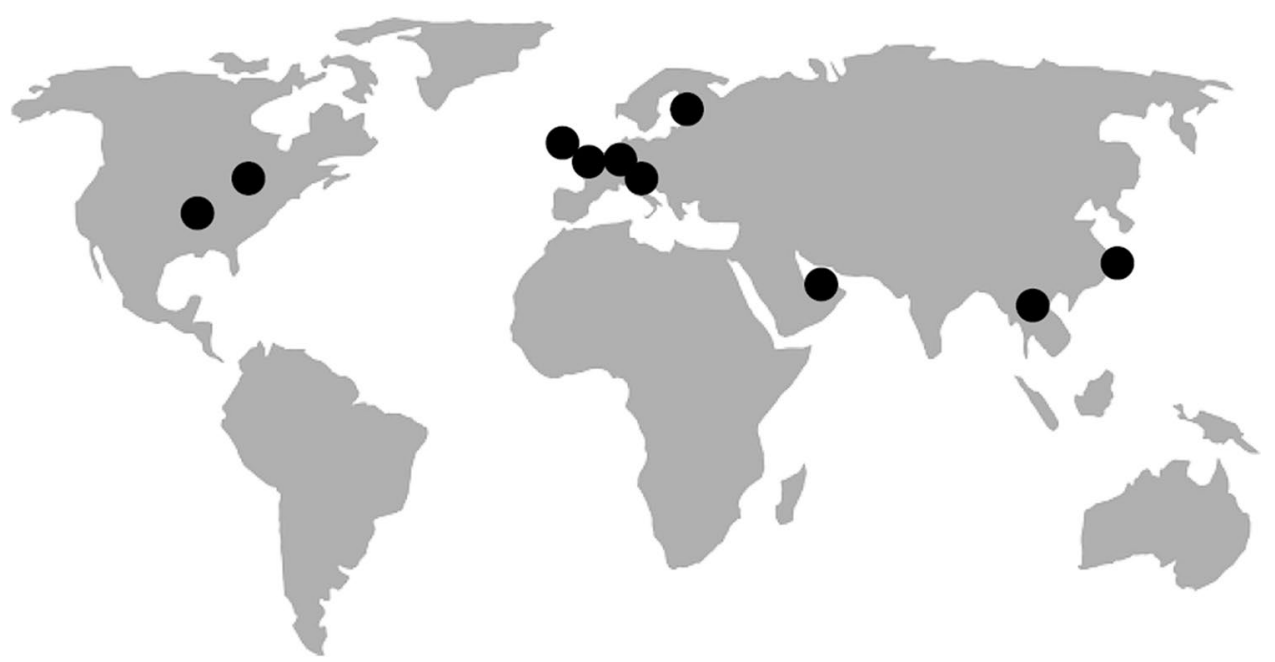

Fig. 2 Ten largest biobanks based on the number of samples (from left to right). "All of Us" biobank, USA, 1 million participants, $3^{\text {rd }}$ largest Canadian Partnership for Tomorrow Project Biobank, Canada, over 300000 participants, $8^{\text {th }}$ largest UK Biobank, Great Britain, 500000 participants, $6^{\text {th }}$ largest The International Agency For Research On Cancer (IARC) Biobank (IBB), France, 562 individuals, $4^{\text {th }}$ largest EuroBioBank Network, European Union, more then
150000 samples, $9^{\text {th }}$ largest Biobank Graz, Austria, 19546888 samples, $1^{\text {st }}$, (=the largest) FINNGEN biobank, Finland, 500000 participants, $7^{\text {th }}$ largest Qatar Biobank (QBB), Qatar, Over 60000 participants, $10^{\text {th }}$ largest China Kadoorie Biobank, China, over 510000 participants, $5^{\text {th }}$ largest Shanghai Zhangjiang Biobank, China, target size 10 million samples, $2^{\text {nd }}$ largest 
diseases, prevention, diagnosis and treatment, offer sources for evaluating local, regional populations, provide data for various studies including cost effectiveness of new screening programmes, new treatments, and finally health care systems.

\section{Biobanking education visions}

There are many aspects of new generation education of biobankers. To underline the most important features, international collaboration and accessibility of samples, associated data basic methods connecting with biobanking and methodologies is essential. Interdisciplinary breakthroughs of various disciplines, innovative approaches, and fast translation of basic research results into practice will make biobanking education actual and ready to solve emerging scientific and healthcare systems problems. Two approaches in biobanking education should be applied: "bottom up" and "top down". Combination of them will assure that will be covered both single things in detail and general aspects as structure, system, and processes. Special attention should be paid to ELSI, as the number of personal data is growing almost exponentially their security and privacy must be provided.

Biobanking education should be structured according to the structure of the whole society. Increase of awareness of biobanking and deeper involvement of patients, donors, public and others will enhance correct understanding and acceptance of biobanks.

Biobanking education should be in close collaboration with industry, to understand well special requirements of pharmaceutical and other industry connected with medical research and healthcare and to benefit from it.

New formats of biobanks will be created, the most advanced form is virtual biobank, virtually connecting real biobanks if different origin, regions, governance, and type, operating on virtual social and expert networks.

\section{Conclusions and expert recommendations}

The market for biobanking education is a big challenge. Europe, the United States and Canada are regions with wellestablished biobanking education, new and fast-growing biobanking countries like China, Qatar also significantly contribute to development and implementation of educational programs [66, 67] (Fig. 2) [68]. On the other hand, there are continents and countries that have emerging needs for biospecimen and biobanking education like Africa and South America [8].

Interesting discussion was initiated by ISBER members $[69,70]$ of "education and training advisory committee" and Regional Ambassadors, about the hottest topics in the given regions in Europe, Middle East, and Africa (EMEA) regions [69]. The common topic for Africa and Russia is training and education for every specialty necessary in biobanking, all forms of education and training, and to have a chance to visit and/or work in the best world biobanks. It was declared that the range and variety of training and educational options is not satisfactory worldwide. The main obstacle is the financial support. That is why the new ideas to established grants for less developed countries and less developed biobanks and "students" from Low- and middleincome countries (LMIC) are now discussed in biobanking community.

To summarise, the future education of new generation of biobankers, should reflect the latest achievements of a wide range of biomedical as well as technical sciences, should be international and multidisciplinary, should be harmonised, and should be innovative. Education should also incorporate principles of modern health care systems based on predictive, preventive and personalised medicine (PPPM/3PM) approaches, and fully accept national and international ethical, legal and societal issues. Education should be able to answer new challenges like pandemics and other unpredictable events.

Funding This work was supported by the Charles University Research Fund (Progres Q39); by the grant of Ministry of Health of the Czech Republic - Conceptual Development of Research Organization (University Hospital Pilsen - FNPI, 00669806); BBMRI-CZ: Biobank network - a versatile platform for the research of the etiopathogenesis of diseases (CZ.02.1.01/0.0/0.0/16_013/0001674); Bank of the clinical samples (LM2018125).

Data availability not applicable.

Code availability not applicable.

\section{Declarations}

Ethics approval The author declares that she has no conflict of interest.

Consent to participate not applicable.

Consent for publication not applicable.

Conflict of interest The author declares that she has no conflict of interest.

\section{References}

1. Hofman P, Bréchot C, Zatloukal K, Dagher G, Clément B. Public-private relationships in biobanking: a still underestimated key component of open innovation. Virchows Arch. 2014;464(1):39. https://doi.org/10.1007/s00428-013-1524-z. 
2. De Souza YG, Greenspan JS. Biobanking past, present and future: responsibilities and benefits. AIDS. 2013;27(3):303-12. https:// doi.org/10.1097/QAD.0b013e32835c1244.

3. Castellanos-Uribe M, Gormally E, Zhou H, Matzke E, Watson PH. Biobanking education. Biopreserv Biobank. 2020;18(1):13. https://doi.org/10.1089/bio.2019.29062.mjc.

4. OECD Principles and Guidelines for Access to Research Data from Public Funding. 2007, OECD Publishing, Paris, https:// doi.org/10.1787/9789264034020-en-fr. https://www.oecd.org/ sti/inno/38500813.pdf. Accessed 7 Jan 2021.

5. OECD Organization for Economic Cooperation and Development. OECD guidelines on human biobanks and genetic research databases. Eur J Health Law. 2010;17(2):191-204. http://www.oecd.org/sti/emerging-tech/44054609.pdf. Accessed 7 Jan 2021.

6. NCI Best Practices for Biospecimen Resources. 2016. https:// biospecimens.cancer.gov/bestpractices/2016-NCIBestPractice s.pdf Accessed 7 Jan 2021.

7. Castellanos-Uribe M, May ST, Betsou F. Integrated BioBank of Luxembourg-University of Luxembourg: University Biobanking Cerftificate. Biopreserv Biobank. 2020;18(1):7-9. https://doi. org/10.1089/bio.2019.0049.

8. Matzke L, O'Donoghue S, Watson PH. UBCx "Biospecimen research methods course." Biopreserv Biobank. 2020;18(1):4-6. https://doi.org/10.1089/bio.2019.0046.

9. Zhou H, Wu X, Zeng L, Yan X, Tian W, Xiong K, et al. The international teaching and practice of cryobiology and biobakology course in China. Biopreserv Biobank. 2020;18(1):10-3. https:// doi.org/10.1089/bio.2019.0104.

10. Kaminski A, Gut G, Uhrynowska-Tyszkiewicz I, Olender E. Tissue banking training courses: Polish experience. Cell Tissue Bank. 2013;14:141-5. https://doi.org/10.1007/s10561-012-9294-4.

11. Abdelhafiz AS, Fouda MA, El-Jaafary SI, Farghly MI, Salem M, Tammam A, et al. Targeting future customers: an introductory biobanking course for undergraduate students of life sciences. Biopreserv Biobank. 2017;15(4):350355. https://doi.org/10.1089/ bio.2016.0111.

12. Ozuorcun NC, Tabak F. Is M-learning versus E-learning or are they supporting each other? Procedia - Social and Behavioural Sciences. 2012;46:299-305. Available online at https://www.scien cedirect.com.

13. Alhassan R. Mobile learning as a Method of ubiquitous learning: students'attitudes, readiness, and possible barriers to implementation in higher education. J Educ Learn. 2016;5(1):176. https://doi. org/10.5539/jel.v5n1p176.

14. Kinkorová J, Topolčan O. Biobanks in the era of big data: objectives, challenges, perspectives, and innovations for predictive, preventive, and personalised medicine. EPMA J. 2020;3:333-41. https://doi.org/10.1007/s13167-020-00213-2.

15. Jiang EP. Enhancing student learning experience with practical big data analytics techniques. In: Zhang Y, Cristol D, editors. Handbook of mobile teaching and learning. Springer Singapore, SpringerLink; 2019. pp. 1205-20. https://doi. org/10.1007/978-981-13-2766-7.

16. Golubnitschaja O, Baban B, Boniolo G, Wang W, Bubnov R, Kapalla M, et al. Medicine in the early twenty-first century: paradigm and anticipation - EPMA position paper 2016. EPMA J. 2016;7:23. https://doi.org/10.1186/s13167-016-0072-4.

17. Macheiner T, Huppertz B, Sargsyan K. The need for special education in biobanking. 2014. https://www.openaccessgovernment .org/need-special-education-biobanking/12036/. Accessed 7 Jan 2021.

18. ISBER education and training opportunities https://www.isber .org/page/Learning. Accessed 7 Jan 2021.

19. Campbell LD, Astrin JJ, Brody R, De Souza Y, Giri JG, Patel AA et al. ISBER Best practices: Recommendations for repositories.
Fourth Edition. Biopreserv Biobank 2018; 1-103. https://doi. org/10.1089/bio-2018-0001.

20. ISBER Educational opportunities/certificates and degrees for repositories https://www.isber.org.page/BiobanEduOpp. Accessed 7 Jan 2021.

21. ISBER Qualification in Biorepository Science (QBRS) https:// www.isber.org/general/custom.asp?page=qualification. Accessed 7 Jan 2021.

22. ESBB European, Middle Eastern \& African Society for Biopreservation and Biobanking. https://esbb.org/. Accessed 7 Jan 2021.

23. ESBB Education \& Training, ESBB Webinars. https://esbb.org/ page/Education. Accessed 7 Jan 2021.

24. BBMRI-ERIC. https://www.bbmri-eric.eu. Accessed 7 Jan 2021.

25. Implementing Biomedical Research Projects: The Complete Workflow from Concept, ELSI and Privacy Considerations to High-Quality Biobanking. https://www.bbmri-eric.eu/wp-conte nt/uploads/EJP-RD_GrazBiomedicalResearchWorkshop_SaveT heDate_v3-1.pdf. Accessed 7 Jan 2021.

26. Brochhausen C, Evert M, Becker K-F, Kinkorova J, Topolcan O, Valík D. 'Big'BRoTHER. Pan European Networks: Health Europa Quarterly 03. 2017; 48-49 http://edition.pagesuiteprofessional.co.uk/html5/reader/production/default.aspx?pubna me $=\&$ edid=4aee2deb-ebd4-4001-a619-9483b4d02811. Accessed 7 Jan 2021.

27. Brochhausen C. edu/BRoTHER: an innovative student exchange programme providing biobvank skills. Health Europe. 2020. https ://www.healtheuropa.eu/edu-brother-providing-biobank-skill s/97180/. Accessed 7 Jan 2021.

28. Master of Science Biobanking. https://postgraduate-school.medun igraz.at/en/universitaetslehrgaenge/masterlehrgaenge/master-ofscience-biobanking/. Accessed 7 Jan 2021.

29. https://wwwfr.uni.lu/studies/fstm/certificate_principles_of_bioba nking. Accessed 7 Jan 2021.

30. EVAg. Biobanking e-learning training. https://postgraduate-schoo 1.medunigraz.at/en/universitaetslehrgaenge/masterlehrgaenge/ master-of-science-biobanking/. Accessed 7 Jan 2021.

31. IARC Training. https://learning.iarc.fr/biobanking/starting-abiobank/. Accessed 7 Jan 2021.

32. Gormally E, Hardy I, Caboux E, di Donato JH, Hainaut P, Hofman P. Training the next generation of biobankers: a two-year master's course in the management of biobanks. Biopreserv Biobank. 2017;15(5):438-50. https://doi.org/10.1089/bio.2017.0002.

33. Labib RM, Mostafa MM, Alfaar AS, et al. Biorepository for pediatric cancer with minimal resources: meeting the challenges. Biopreserv Biobank. 2016;14(1):9-16. https://doi.org/10.1089/ bio.2015.0004.

34. Barr MP, Souan L, MacGabhann P, et al. The establishment of an ISO compliant cancer biobank for Jordan and its neighboring countries through knowledge transfer and training. Biopreserv Biobank. 2014;12(1):3-12. https://doi.org/10.1089/ bio.2013.0072.

35. Al Kuwari H, Al Thani A, Al Marri A, et al. The Qatar Biobank: background and methods. BMC Public Health. 2015;15:1208. https://doi.org/10.1186/s12889-015-2522-7.

36. Salman A, Baber R, Hannigan L, et al. Qatar Biobank milestones in building a successful biobank. Biopreserv Biobank. 2019;17(6):485-6. https://doi.org/10.1089/bio.2019.0083.

37. Alahmad G, Dierickx K. Return of research results in the Saudi Biobank: an exploratory survey. Genet Test Mol Biomarkers. 2017;21(3):166-70. https://doi.org/10.1089/gtmb.2016.0396.

38. Golubnitschaja O, Kinkorová J, Costigliola V. Predictive, preventive and personalised medicine as the hardcore of "Horizon 2020": EPMA position paper. EPMA J 2014; 5:6. http://www.epmajourna 1.com/content/5/1/6. Accessed 7 Jan 2021.

39. EPMA Journal, https://www.springer.com/journal/13167. Accessed 7 Jan 2021. 
40. Commission Directive 2006/86/EC of 24 October 2006 implementing Directive 2004/23/EC of the European Parliament and of the Council as regards traceability requirements, notification of serious adverse reactions and events and certain technical requirements for the coding, processing, preservation, storage and distribution of human tissues and cells (2006). Off J Eur Union. 2006; L 294/37-50.

41. Kinkorová J, Topolčan O. Biobanks in Horizon 2020: sustainability and attractive perspectives. EPMA J. 2018;9:345-53. https:// doi.org/10.1007/s13167-018-0153-7.

42. B3Africa http://www.b3africa.org/. Accessed 7 Jan 2021.

43. DRYNET https://drynet.unite.it/. Accessed 7 Jan 2021.

44. DRYSTORE https://drystore.unite.it/. Accessed 7 Jan 2021.

45. SPIDIA4P https://www.spidia.eu/. Accessed 7 Jan 2021.

46. SIMICA https://simica.imm.medicina.ulisboa.pt/project/. Accessed 7 Jan 2021.

47. WIDENLIFE https://sisu.ut.ee/widenlife. Accessed 7 Jan 2021.

48. LifeCycle https://lifecycle-project.eu/. Accessed 7 Jan 2021.

49. BonePain http://bonepain.eu/. Accessed 7 Jan 2021.

50. Biotem https://300k.bio/biotem-project/. Accessed 7 Jan 2021.

51. TrainCKDis https://cordis.europa.eu/project/id/860977. Accessed 7 Jan 2021

52. https://www.thermofisher.com/cz/en/home/clinical/biobanking/ biobanking-learning-center.html. Accessed 7 Jan 2021.

53. https://www.agilent.com/en/training-events/events/agilent-unive rsity. Accessed 7 Jan 2021.

54. https://www.autoscribeinfor matics.com/services/training. Accessed 7 Jan 2021

55. https://www.bruker.com/service/education-training.html. Accessed 7 Jan 2021.

56. http://farrarscientific.com/. Accessed 7 Jan 2021.

57. https://www.fluidigm.com/training. Accessed 7 Jan 2021.

58. https://www.labvantage.com/our-services/training/. Accessed 7 Jan 2021

59. https://swiftbiosci.com/summer-webinar-series/. Accessed 7 Jan 2021.

60. Hood L, Price ND. Demystifying disease, democratizing health care. SciTransl Med. 2014;6(225):225ed5. https://doi. org/10.1126/scitranslmed.3008665.

61. Beckmann JS, Lew D. Reconciling evidence-based medicine and precision medicine in the era of big data: challenges and opportunities. Genome Med. 2016;8:134. https://doi.org/10.1186/s1307 3-016-0388-7.
62. Coppola L, Cianflone A, Grimaldi AM, Incoronato M, Bevilacqua $\mathrm{P}$, Messina $\mathrm{F}$, et al. Biobanking in health care: evolution and future directions. J Transl Med. 2019;17:172-90. https://doi. org/10.1186/s12967-019-1922-3.Accessed7Jan2021.

63. Kozlakidis Z, Lewandowski D, Betsou F. Precision medicine and biobanking: Future directions. 2018. https://www.openaccess government.org/precision-medicine-biobanking-inchina/51731/. Accessed 7 Jan 2021.

64. Liu A, Pollard K. Biobanking for personalized medicine. Adv Exp Med Biol. 2015;864:55-68. https://doi.org/10.1007/978-3-31920579-3_5.

65. Patel A. Tissue banking for Research-bench to bedside and backmyth, reality or fast fading reality at the dawn of a personalised healthcare era. Cell Tissue Bank. 2011;12:19-21. https://doi. org/10.1007/s 10561-010-9206-4.

66. Chen J, Kozlakidis Z, Cheong IH, Zhou X. Precision medicine research and biobanking in China. 2019. https://www.openaccess government.org/precision-medicine-biobanking-inchina/77789/. Accessed 7 Jan 2021.

67. Salman A, Baber R, Hannigan L, Habermann JK, Henderson MK, Mayerhofr MT, et al. Quality matters: a global discussion in Qatar. Biopreserv Biobank. 2019;17(6):487-90. https://doi.org/10.1089/ bio.2019.0073.

68. Orchard-Webb D. 10 Largest Biobanks in the World. Biobanking. com, https://www.biobanking.com/10-largest-biobanks-in-theworld/ Accessed 7 Jan 2021.

69. Byrne JA, Green C, Hill K, Kozlakidis Z, de Wilde A, Mullis P, et al. The expert speak on biobank education. BiopreservBiobank. 2020;18(1):14-7. https://doi.org/10.1089/bio.2020.29064.sod.

70. Afifi NM, Anisimov SV, Aguilar-Quesada R, Kinkorova J, Marrs S, Nassimbwa S, et al. Biobanking spotlight on Europe, Middle East, and Africa: presenting the collective experience of the ISBER-EMEA Regional Ambassadors. Biopreserv Biobank. 2020;18(5):471-8. https://doi.org/10.1089/bio.2020.0013.

Publisher's note Springer Nature remains neutral with regard to jurisdictional claims in published maps and institutional affiliations. 